\title{
Application of hybrid materials in solid-state electrochromic devices
}

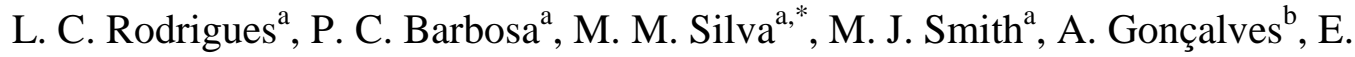 \\ Fortunato $^{b}$ \\ ${ }^{a}$ Centro de Química, Universidade do Minho, Gualtar, 4710-057 Braga, Portugal \\ ${ }^{\mathrm{b}}$ Centro de Investigação de Materiais,CENIMAT, Campus da FCT 2829 - 516 Caparica \\ Portugal
}

\begin{abstract}
Sol-gel derived cross-linked PEO/siloxane xerogels (designated as di-ureasils) were prepared using lithium trifluoromethanesulfonyl imide (LiTFSI) as a guest salt. In this paper we describe the assembly of a prototype solid-state electrochromic device (ECD) based on a four-layer sandwich structure, with the following configuration: glass/IZO/ $\mathrm{WO}_{3} /$ polymer electrolyte/IZO/glass. The electrochromic switching performance of these devices was characterized as a function of salt concentration. The average transmittance in the visible region of the spectrum was above $69 \%$ for all the bleached samples characterized. After coloration the structures assembled with d-U(900) ${ }_{\mathrm{n}} \mathrm{LiTFSI}$ presented an average transmittance in the visible wavelength region above $22 \%$ and an optical density above 0.49 .
\end{abstract}

PACS codes: 42.70.J; 78.66.Q ; 85.60.P

Keywords: Organic-inorganic hybrid electrolytes, sputtering, electrochromic materials.

\footnotetext{
Corresponding author: Tel:+351 253604370. Fax: +351 253604382. Email: nini@quimica.uminho.pt
} 


\section{Introduction}

Certain materials show the capacity to undergo reversible coloration through the introduction and removal of ionic guest species. These electrochromic materials have been attracting significant attention, partly due to academic interest in their properties but also because of the potential commercial impact of their technological applications. Examples of successful electrochromic devices already exist in rear-view mirrors for vehicles that automatically dim to avoid dazzle or smart windows that adjust the properties of the active layer to control incident sunlight transmission [1-3]. It is likely that further development will result in an increase in the number of these devices in domains with even greater commercial importance such as smart time-lapse, temperature-fluctuation labels [4] or reactive sun-roofs. A critical component in electrochromic devices is the ion-conducting electrolyte. Lithium-based electrolytes have been proposed for application in devices due to the long-term stability for solid-state smart window application and because the diffusion coefficient of the lithium ion in $\mathrm{WO}_{3}$ is higher than that of other metallic cations [5].

Organic-inorganic hybrid electrolytes are innovative materials with electrochemical and mechanical behaviour suitable for a wide range of practical applications. The main synthetic route for the formation of these advanced systems is the sol-gel method [6]. In the last few years, the use of hybrid materials has been increasingly adopted for the production of low cost polymer networks with potentially-attractive features for optical devices [7]. The preparative strategies developed can be readily modified to produce thin-film electrolyte sections with appropriate chemical, electrochemical and mechanical properties. 
In this paper we describe the fabrication and evaluation of a prototype solid-state electrochromic device based on a four-layer sandwich structure with the following configuration: glass/IZO/ $\mathrm{WO}_{3} / \mathrm{d}-\mathrm{U}(900)_{\mathrm{n}} \mathrm{LiTFSI} / \mathrm{IZO} /$ glass.

\section{Experimental}

\subsection{Materials}

Lithium bis(trifluoromethansulfonyl)imide was dried under vacuum at $190^{\circ} \mathrm{C}$ for 7 days and then stored in a dry argon-filled glovebox with a water content lower than 10 ppm. The O,O'-bis(2-aminopropyl) polyethylene glycol (commercially available as Jeffamine ED-900®, Fluka, average molecular weight $900 \mathrm{gmol}^{-1}$ ) was dried under vacuum at $25^{\circ} \mathrm{C}$ for several days prior to use. The bridging agent, 3-isocyanatepropyltriethoxysilane (ICPTES, Aldrich $95 \%$ ), was used as received. Ethanol $\left(\mathrm{CH}_{3} \mathrm{CH}_{2} \mathrm{OH}\right.$, Merck, 99.8\%) and tetrahydrofuran (THF, Merck, 99.9\%) were dried over molecular sieves. High purity distilled water (Millipore) was used in all experiments.

\subsection{Samples preparation}

The synthesis of $\mathrm{Li}^{+}$-doped di-ureasils has been described in detail elsewhere [8,9]. The framework of these xerogels, represented by $\mathrm{U}(900)$, contains oxyethylene segments with about 15 repeat units bonded at each end to a siliceous backbone through urea bridges. In accordance with the conventional nomenclature, electrolyte composition was expressed as d-U(900) $)_{\mathrm{n}}$ LiTFSI where $\mathrm{n}$ represents the molar ratio of oxyethylene moieties to $\mathrm{Li}^{+}$ions. The procedure used for $\mathrm{d}-\mathrm{U}(900)_{\mathrm{n}} \mathrm{LiTFSI}$ involved grafting a diamine containing approximately 15 oxyethylene repeat units onto the ICPTES precursor, to yield the di-urea bridged hybrid precursor (Scheme 1). This material was subsequently 
hydrolyzed and condensed in the sol-gel stage of the synthesis to induce the growth of the siloxane framework.

Step 1 - Synthesis of the di-ureasil precursor, d-UPTES(900): $2.0 \mathrm{~g}$ of Jeffamine ED900® was dissolved in $10 \mathrm{ml}$ of THF with stirring. A volume of $1.097 \mathrm{~mL}$ of ICPTES was added to this solution in a fume cupboard (molar proportion 1 Jeffamine ED-900®: 2 ICPTES). The flask was then sealed and the solution stirred for about $12 \mathrm{~h}$ at moderate temperature $\left(\approx 40^{\circ} \mathrm{C}\right)$. A urea cross-linked organic-inorganic material, designated as diureapropyltriethoxysilane (d-UPTES(900)), was obtained under these conditions.

Step 2 - Synthesis of the di-ureasil xerogels, $d$-U(900) ${ }_{n}$ LiTFSI: A volume of $1.038 \mathrm{~mL}$ of $\mathrm{CH}_{3} \mathrm{CH}_{2} \mathrm{OH}$, an appropriate mass of LiTFSI and $0.120 \mathrm{~mL}$ of water were added to the dUPTES(900) solution prepared in the previous step (molar proportion 1 ICPTES: 4 $\mathrm{CH}_{3} \mathrm{CH}_{2} \mathrm{OH}$ : $1.5 \mathrm{H}_{2} \mathrm{O}$ ). The mixture was stirred at room temperature in a sealed flask for approximately $30 \mathrm{~min}$ and then decanted into a Teflon ${ }^{\circledR}$ mould, covered with perforated membrane of Parafilm ${ }^{\circledR}$ and stored in a fume cupboard for $24 \mathrm{~h}$. After this period the mould was transferred to an oven at $50^{\circ} \mathrm{C}$ and the sample was aged for a period of 3 weeks. A final period of 1 week at $80^{\circ} \mathrm{C}$ completed the process.

Transparent Conductive Oxide: Indium zinc oxide (IZO) films were deposited on glass substrates by r.f. (13.56 MHz) magnetron sputtering using a ceramic oxide target of $\mathrm{ZnO} / \mathrm{In}_{2} \mathrm{O}_{3}(5 \mathrm{~cm}$ diameter, from Super Conductor Material, Inc., purity of $99.99 \%)$. The sputtering was carried out at room temperature, with a partial pressure of oxygen of $2.5 \times 10^{-}$

${ }^{3} \mathrm{~Pa}$ with a constant deposition pressure of $0.15 \mathrm{~Pa}$. The distance between the substrate and the target was $10 \mathrm{~cm}$ and the rf power was held constant at $100 \mathrm{~W}$. Details concerning the film preparation as well as the physical properties can be found in ref [10]. 
Electrochromic film: the tungsten oxide films $\left(\mathrm{WO}_{3}\right)$ were prepared by thermal evaporation using $\mathrm{WO}_{3}$ pellets (SCM, 99.99\% purity). The deposition pressure was 1.6x10${ }^{3} \mathrm{~Pa}$.

\subsection{Electrochromic cell assembly, Substrate A / d-U(900)niTFSI/ Substrate B}

Electrolyte compositions were prepared by direct application of a small volume of the d-U(900) $)_{n} \mathrm{LiTFSI}$ ormolyte to the surface of a glass plate onto which a $\mathrm{IZO} / \mathrm{WO}_{3}$ coating had been previously deposited. The gel was dried in a vacuum oven for a period of 7 days. The thicknesses used for the electrolyte, IZO and $\mathrm{WO}_{3}$ component layers were 100, 170 and $400 \mathrm{~nm}$ respectively. A second IZO-coated glass plate was placed on top of the dry electrolyte layer and the two plates were pressed together to spread the electrolyte in a thin film between the electrochromic surfaces. The entire assembly procedure described was carried out under a laboratory atmosphere. The prototype solid-state electrochromic device structure is represented schematically in Figure 1.

\section{Results and Discussion}

\section{1 - Electrochemical behaviour of the d-U(900) ${ }_{n}$ LiTFSI electrolytes}

Research in the domain of solid polymer electrolytes has been growing rapidly since it was accepted that solid state ionic conductors could substitute liquid electrolytes in electrochemical devices. Apart from presenting ionic conductivities suitable for use in electrochemical devices such as solid-state smart windows, polymer electrolytes also eliminates problems concerning evaporation or leakage of the solvent. For successful applications in electrochemical applications, polymer electrolytes should present

conductivities better than $10^{-5} \mathrm{~S} / \mathrm{cm}$ in the temperature range from $-20^{\circ} \mathrm{C}$ to $60^{\circ} \mathrm{C}$, have good 
mechanical, thermal stability and a wide electrochemical stability window [11]. For application in electrochromic devices, polymer electrolytes should present high transparency to intensify the chromatic contrast of the device.

The SPE system presented in this paper was characterized by ionic conductivity measurements, cyclic voltammetry at a gold microelectrode and thermal analysis and demonstrated to be adequate for application on electrochromic devices [12]. The conductivity behaviour of all polymer electrolytes based on d-U(900) and LiTFSI was found to show a non-linear variation of $\log$ conductivity with $1 / \mathrm{T}$ in the range between 25 and $100^{\circ} \mathrm{C}$. The most conducting composition of this system is d-U(900) ${ }_{15} \mathrm{LiTFSI}$ which reaches $7.6 \times 10^{-5} \mathrm{ohm}^{-1} \mathrm{~cm}^{-1}$ at $95^{\circ} \mathrm{C}$. At room temperature the composition with the highest conductivity is d-U(900) ${ }_{25} \operatorname{LiTFSI}\left(2.9 \times 10^{-6} \mathrm{ohm}^{-1} \mathrm{~cm}^{-1}\right)$. The results of thermal analysis of the d-U(900) ${ }_{n}$ LiTFSI electrolytes confirm that the samples with $n$ ranging from 200 to 5 are completely amorphous and the lowest decomposition temperature observed with the d$\mathrm{U}(900)_{\mathrm{n}} \mathrm{LiTFSI}$ system was registered for the $\mathrm{n}=40$ composition $\left(358^{\circ} \mathrm{C}\right)$.

Electrochemical stability with a wide potential range is necessary for electrochemical devices such as primary and secondary batteries and electrochromic displays. The electrochemical stability of the electrolyte was determined by microelectrode cyclic voltammetry over the potential range -2.0 to $7.0 \mathrm{~V}$. The potential limit for the electrolyte system was determined as the potential at which a rapid rise in current was observed and where the current continued to increase as the potential was swept in the same direction.

The overall stability of the electrolytes is good with no electrochemical oxidation occurring at potentials less than $5 \mathrm{~V}$ versus $\mathrm{Li} / \mathrm{Li}^{+}$. This result confirms the applicability of this electrolyte composition also presents a broad stability window $\left(5 \mathrm{~V} \mathrm{Li} / \mathrm{Li}^{+}\right)$, which confirm the applicability of this SPE system to electrochromic devices. 


\section{2 - Electrochromic structure device}

The difference in the transmittance between the colored (written) state and the fully bleached (unwritten) state indicates the light modulation capability of electrochromic devices. A SPE component in an optical device must meet various pre-requisites. One of these is that the film must exhibit high transmission. If this condition is not fulfilled the electrolyte will reduce the colour contrast of the optical device [13].

The scheme in Figure 1 shows the prototype device assembly of the electrochemical display characterized in preliminary experiments. The evaluation of devices based on d$\mathrm{U}(900)_{\mathrm{n}} \mathrm{LiTFSI}$ di-ureasils confirmed that the active layer of the assembled device changed from almost transparent to a blue color associated with $\mathrm{WO}_{3}$ reduction and simultaneous $\mathrm{Li}^{+}$insertion as a result of the application of a positive voltage (Figure 2). Inversion of the applied voltage resulted in $\mathrm{WO}_{3}$ oxidation and the device should returned to its initial state. The coloring voltage used in the electrochromic prototypes were $1.5 \mathrm{~V}$ during 30 seconds. With future studies we expect this hybrid electrolyte to have adequate optical density, good stability and good optical memory. Figure 3 shows the optical transmittance in the wavelength range 400-800 $\mathrm{nm}$ for the preliminary electrochromic devices (ECDs) based on d-U(900) $)_{n}$ LiTFSI di-ureasils, which represent the compositions with best optical

performance transparency and excellent mechanical properties. These samples also correspond to electrolyte compositions with highest ionic conductivity [12]. Electrolytes have been one of the most challenging components in the development of reliable solidstate electrochemical devices. The electrolyte serves as an ion store that exchanges charged species over the electrode-electrolyte interface during the electrochemical process, thus maintaining the overall electroneutrality of the system. 
Table I summarizes the average transmittance (in the visible part of the spectrum) and optical density exhibited by the electrochromic devices.

The average transmittance in the visible region of the spectrum was above $69 \%$ for all the bleached samples analyzed. After coloration the structures assembled with d$\mathrm{U}(900)_{5} \mathrm{LiTFSI}$ and d-U(900) ${ }_{40}$ LiTFSI ormolytes, presented a good color contrast (above $24 \%$ ) and an optical density above 0.49 , providing a good performance in coloring/bleaching process (Figure 4). These results are very satisfactory, especially when compared to those obtained with the incorporation of $\mathrm{d}-\mathrm{U}(900)_{\mathrm{n}} \mathrm{LiClO}_{4}$ electrolytes [7]. The reasons for the variation of optical density with electrolyte composition observed in Figure 4 are not yet clear and require further study. The results are consistent with mechanical interfacial effects or the supply of ions due to higher ionic conductivity, both aspects of electrolyte performance that vary significantly with composition.

The encouraging results observed in this exploratory study confirm the advantages that derive from the use of di-ureasil matrices in ECDs. Clearly further optimization of the procedures (like for example the use of a counter electrode based on $\mathrm{NiO}$ as well as an appropriate sealant should be used to avoid the degradation of the polymer) is required and improvements in device response time and optical transmittance under open circuit voltages may be expected.

\section{Conclusions}

In this work novel di-ureasil d-U(900) composites incorporating LiTFSI guest salt were investigated and used as multi-functional components in prototype electrochromic devices. All the devices incorporating d-U(900)nLiTFSI electrolytes presented good stability and storage properties under open circuit. 
The encouraging results obtained with electrochromic smart windows based on diureasil matrices doped with LiTFSI, provide motivation for future optimization studies and improvements in device response time, optical transmittance and memory effect under open circuit voltages may be expected.

\section{Acknowledgements}

The authors are pleased to acknowledge the support provided by the University of Minho and the Fundação para a Ciência e a Tecnologia (contracts POCI/QUI/59856/2004, POCTI/SFA/3/686) for laboratory equipment, research staff grants (contracts SFRH/BD/22707/2005 and SFRH/BD/38616/2007).

\section{References}

[1] C. G. Granqvist, Solid State Ionics, 53-56 (1992) 479.

[2] C. G. Granqvist, Solar Energy Materials \& Solar Cells, 60 (2000) 201.

[3] E. Syrrakou, S. Papaefthimiou and P. Yianoulis, Solar Energy Materials \& Solar Cells, 85 (2005) 205

[4] P. Wang; Q. Dai; S M. Zakeeruddin; M. Forsyth; D. R. MacFarlane; M. Graetzel, J. American Chemical Society 126 (2004) 13590.

[5] E. Masetti, D. Dini, F. Decker, Solar Energy Materials and Solar Cells 39 (1995) 301.

[6] C.J. Brinker, Scherer GW (1990) Sol-gel Science: The Physics and Chemistry of SolGel Processing. Academic Press, San Diego CA. 
[7] P. C. Barbosa, M. M. Silva, M. J. Smith, A. Gonçalves, E. Fortunato, Electrochimica Acta 52 (2007) 2938-2943.

[8] S.M. Gomes Correia, V. de Zea Bermudez, M.M. Silva, S. Barros, R.A. Sá Ferreira, L.D. Carlos, A.P. Passos de Almeida, M.J. Smith, Electrochimica Acta 47 (2002) 2421.

[9] S.C. Nunes, V. de Zea Bermudez, D. Ostrovskii, L.D. Carlos, Journal of Molecular Structure 702 (2004) 39.

[10] E. Fortunato, A. Pimentel, A. Gonçalves, A. Marques, R. Martins, Thin Solid Films 502 (2006) 104.

[11] W. H. Meyer, Adv. Mater. 6 (1998) 439.

[12] P. C. Barbosa, L. C. Rodrigues, M. M.Silva, M. J. Smith, J. Power Sources 180 (2008) 607.

[13] M-H. Cui, Jun-Shi Guo, H-Q., Xie, Z-H. Wu, S-C. Qiu, Journal of Applied Polymer Science 65 (1997) 1739.

\section{Figure Captions}

Scheme 1. Synthesis of the d-U(900) ${ }_{\mathrm{n}}$ LiTFSI ormolytes.

Figure 1. Schematic illustration of the electrochromic structure device.

Figure 2. Electrochromic device in colored state for selected compositions: a) dU(900) $)_{5}$ LiTFSI, b) d-U(900) ${ }_{10}$ LiTFSI, c) d-U(900) ${ }_{30}$ LiTFSI, d) d-U(900) ${ }_{40}$ LiTFSI.

Figure 3. Optical transmittance as a function of wavelength for the electrochromic device in colored state using (a) d-U(900) ${ }_{5}$ LiTFSI; (b) d-U(900) ${ }_{10}$ LiTFSI; (c) d-U(900) ${ }_{15}$ LiTFSI; (d) d-U(900) ${ }_{30}$ LiTFSI; e) d-U(900) ${ }_{40}$ LiTFSI.

Figure 4. Optical density at 620nm of selected electrolytes compositions. 


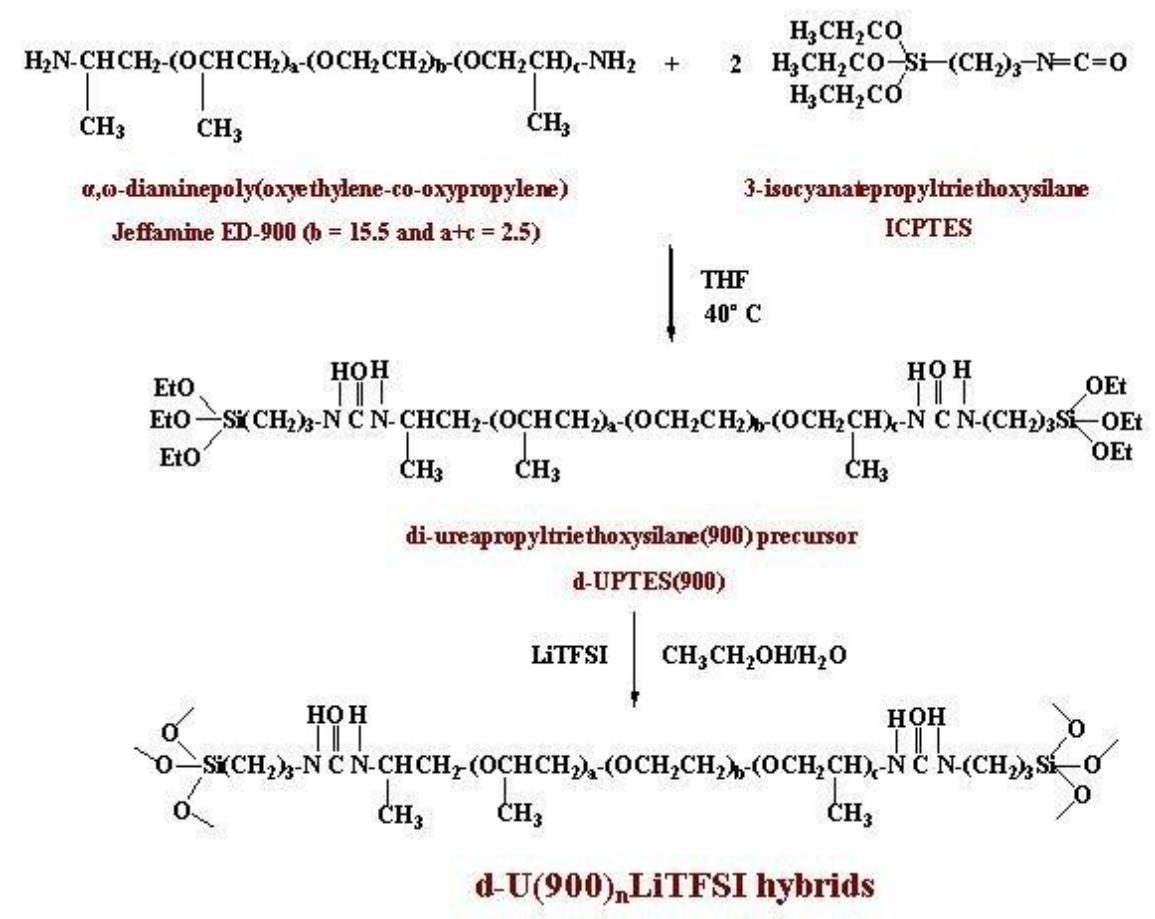

Scheme 1 


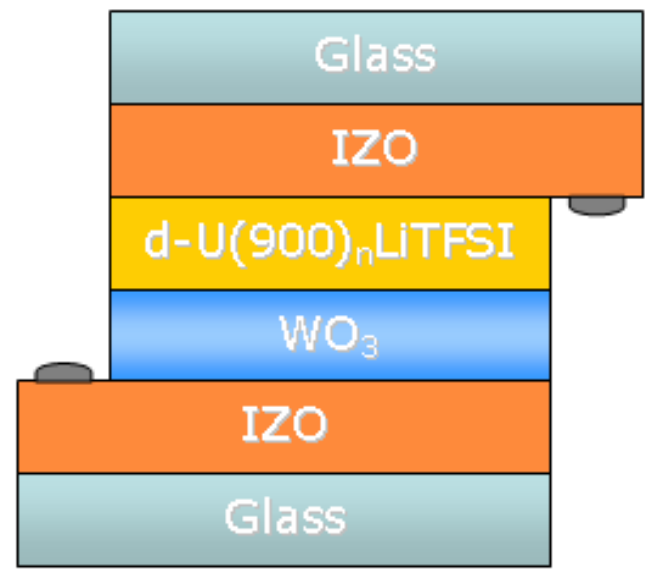

Figure 1 

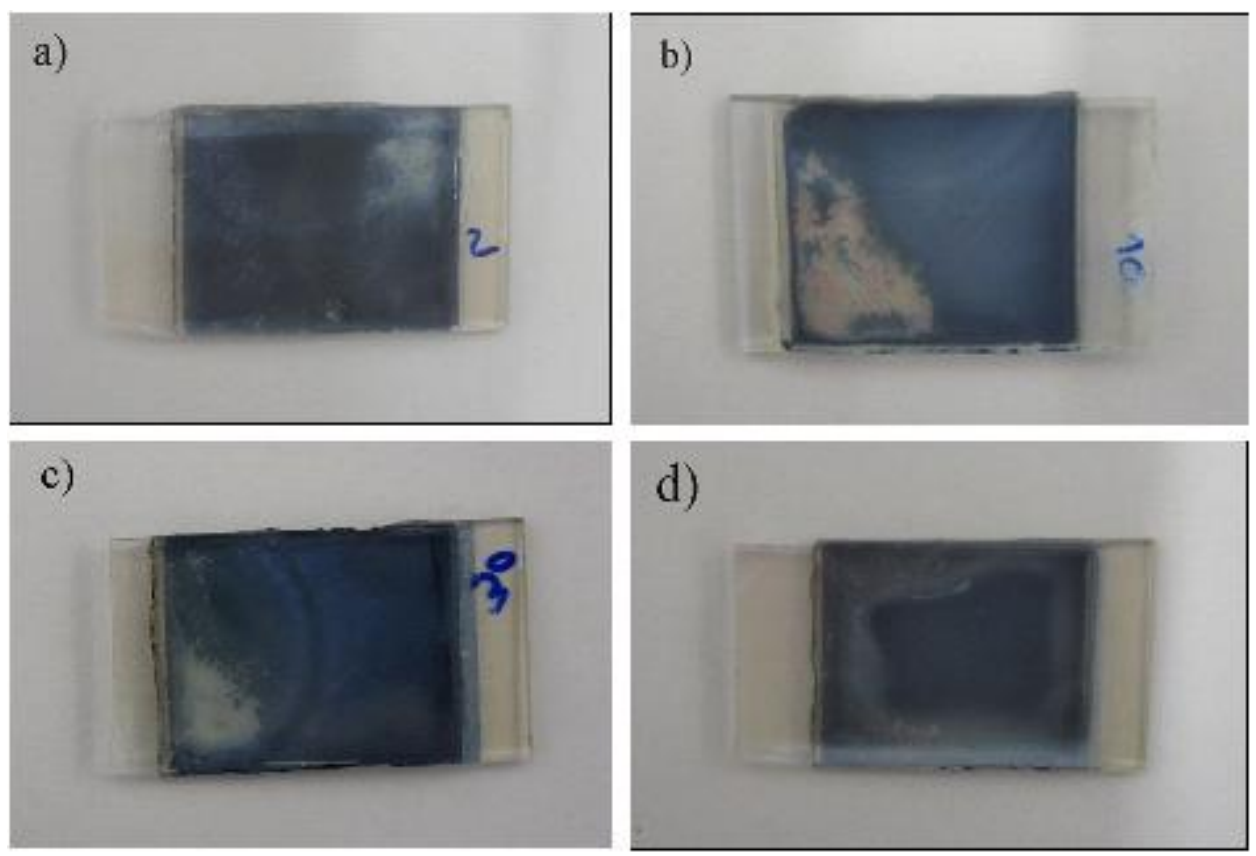

Figure 2 

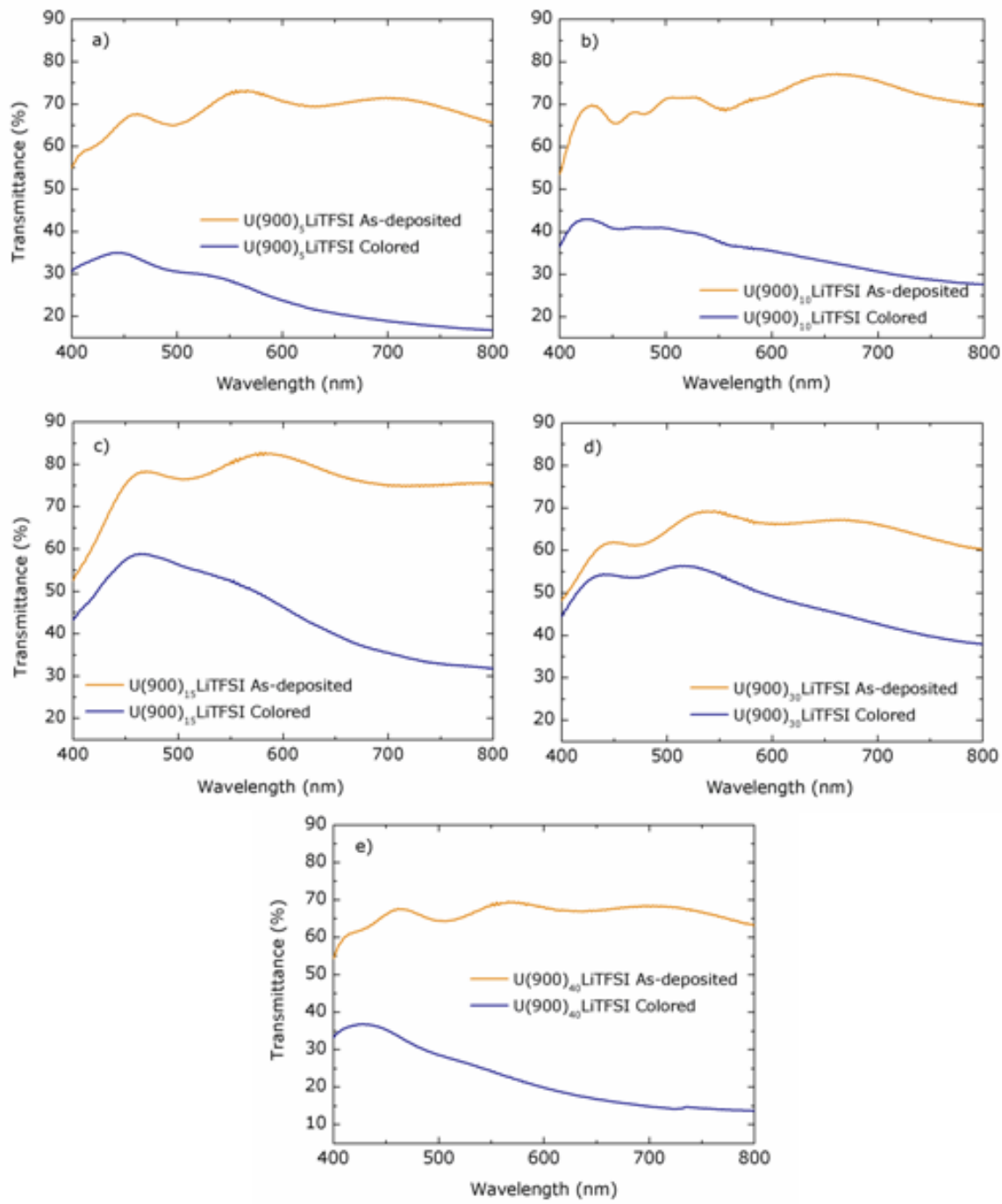

Figure 3 


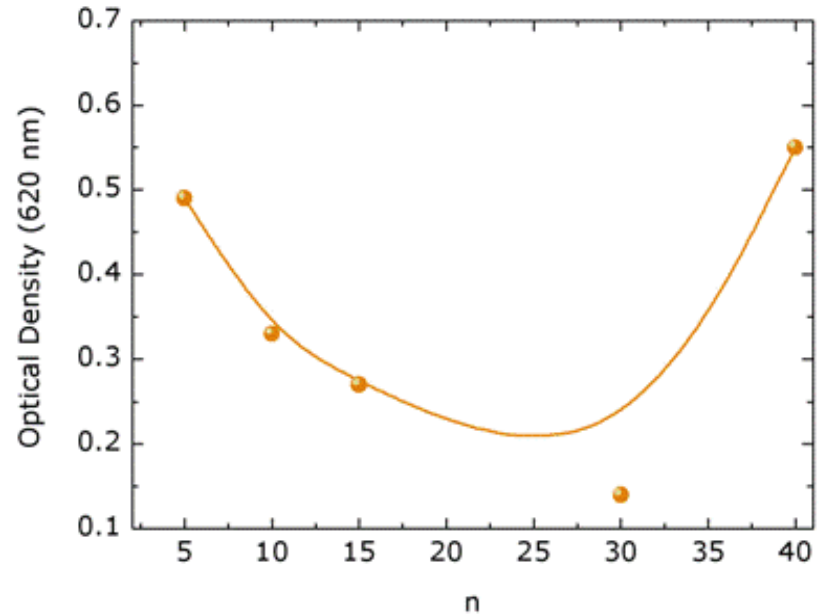

Figure 4 


\section{Table 1}

Average transmittance and optical density exhibited by electrochromic devices using d$\mathrm{U}(900)_{\mathrm{n}} \mathrm{LiTFSI}$.

\begin{tabular}{cccc}
\hline Sample & $\begin{array}{c}\text { Transmittance in } \\
\text { bleached state }(\%)\end{array}$ & $\begin{array}{c}\text { Transmittance in } \\
\text { colored state }(\%)\end{array}$ & $\begin{array}{c}\text { Optical density } \\
(620 \mathrm{~nm})\end{array}$ \\
\hline $\mathrm{U}(900)_{5}$ LiTFSI & 68 & 25 & 0.49 \\
$\mathrm{U}(900)_{10}$ LiTFSI & 71 & 35 & 0.33 \\
$\mathrm{U}(900)_{15}$ LiTFSI & 76 & 45 & 0.27 \\
$\mathrm{U}(900)_{30}$ LiTFSI & 64 & 48 & 0.14 \\
$\mathrm{U}(900)_{40}$ LiTFSI & 66 & 22 & 0.55 \\
\hline
\end{tabular}

